\title{
Lysophosphatidic acid induces expression of genes in human oral keratinocytes involved in wound healing
}

Hong Huynh Thorlakson ${ }^{1,2^{*}}$, Stian Andre Engen ${ }^{1}$, Olav Schreurs ${ }^{1}$, Karl Schenck ${ }^{1}$, Inger Johanne Schytte Blix ${ }^{1,2}$

${ }^{1}$ Department of Oral Biology, Faculty of Dentistry, University of Oslo, Norway

${ }^{2}$ Department of Periodontology, Faculty of Dentistry, University of Oslo, Norway

Running title: LPA responses in oral keratinocytes

*Correspondence to:

Hong Huynh Thorlakson

Department of Oral Biology and Department of Periodontology

Faculty of Dentistry, University of Oslo

PB 1052 Blindern

$\mathrm{N}-0316$ Oslo

Norway

Office Phone: +4722840269 Telefax: $+\underline{4722840302}$ E-mail: hongtth@odont.uio.no

Keywords: oral keratinocyte, LPA, wound healing, inflammation, MAPK, gene 


\section{Abstract}

Objective: Epithelial cells participate in wound healing by covering wounds, but also as important mediators of wound healing processes. Topical application of the phospholipid growth factor lysophosphatidic acid (LPA) accelerates dermal wound healing and we hypothesized that LPA can play a role in human oral wound healing through its effects on human oral keratinocytes (HOK).

Design: HOK were isolated from gingival biopsies and exposed to LPA. The LPA receptor profile, signal transduction pathways, gene expression and secretion of selected cytokines were analyzed.

Results: HOK expressed the receptors $\mathrm{LPA}_{1}, \mathrm{LPA}_{5}$ and $L P A_{6}$ and $L P A$ activated the ERK1/2, JNK and p38 intracellular pathways, substantiated by secretion of IL- 6 and IL-8. The early $(2 \mathrm{~h})$ and intermediate $(6 \mathrm{~h})$ gene expression profiles of HOK after LPA treatment showed a wide array of regulated genes. The majority of the strongest upregulated genes were related to chemotaxis and inflammation, and became downregulated after $6 \mathrm{~h}$. At $6 \mathrm{~h}$, genes coding for factors involved in extracellular matrix remodeling and re-epithelialization became highly expressed. IL-36y, not earlier known to be regulated by LPA, was strongly transcribed and translated but not secreted.

Conclusions: After stimulation with LPA, HOK responded by regulating factors and genes that are essential in wound healing processes. As LPA is found in saliva and is released by activated cells after wounding, our results indicate that LPA has a favorable physiological role in oral wound healing. This may further point towards a beneficial role for application of LPA on oral surgical or chronic wounds. 


\section{Introduction}

Lysophosphatidic acid (LPA) is a growth factor-like lipid, and its biological effects on cells are mediated via G protein-coupled receptors, termed LPA $1-6$ (Yanagida, Kurikawa, Shimizu \& Ishii, 2013). LPA is a natural constituent of mammalian tissue fluids such as plasma, broncho-alveolar lavage fluid (Zhao \& Natarajan, 2009), saliva (Sugiura et al., 2002) and gingival crevicular fluid (GCF) Bathena et al., 2011). LPA is produced by a number of cell types, including erythrocytes, leukocytes, activated platelets and human gingival fibroblasts (Blaho \& Hla, 2011; Cerutis et al., 2015; Eichholtz, Jalink, Fahrenfort \& Moolenaar, 1993).

Wound healing is a dynamic process that involves four major processes that overlap in time (Martin, 1999; Eming et al., 2007): hemostasis, inflammation, tissue formation, and remodeling and maturation. Several observations indicate that LPA plays a role in wound healing in skin and intestine. In vitro, LPA increases migration of human skin keratinocytes and rat intestinal epithelial cells (Sauer et al., 2004; Sturm, A et al. 1999). In vivo, it accelerates repair of injured epithelia in rats with colitis (Sturm, A et al. 1999), wound closing of rat skin (Balazs et al., 2002) and re-epithelialization during the early stages of wound healing in excisional ear wounds in mice (Demoyer et al., 2000). In vitro studies have also shown that LPA increases rodent epidermal cell proliferation in vitro and after topical application of LPA on intact skin in vivo (Piazza GA, 1995). Wound healing in the oral cavity is mostly uncomplicated and without much scarring (Wong et al., 2009), but it can be compromised in certain patients, e.g. those receiving radio- or chemotherapy (RaberDurlacher et al., 2013) or medication against osteoporosis (Marx, 2003).

Little is known about the functions of LPA in the oral cavity. LPA, used at physiological concentrations in saliva, has been shown to increase proliferation of squamous carcinoma cells from the mouth, pharynx and esophagus (Sugiura et al., 2002). In patients with chronic periodontitis, the concentration of LPA has been shown to be 5-10 times higher in saliva and gingival crevicular fluid as compared with healthy subjects (Bathena et al., 2011). The gene expression profile of LPA-stimulated oral fibroblasts is characterized by up-regulation of inflammatory and wound healing genes as compared with unstimulated cells (Cerutis et al., 2015)

Transcriptional profiling is a valuable tool to indicate unknown activities and profiling of LPA-stimulated murine embryonal fibroblasts unveiled activities of LPA in tissue 
remodeling, angiogenesis, inflammation and tumor progression (Stortelers, Kerkhoven \& Moolenaar, 2008). The transcriptional response to LPA in oral epithelial cells is unexplored. As LPA modulates wound healing in the skin and the intestine, we presently aim to find support for the hypothesis that LPA can contribute to wound healing in the oral cavity through its effects on oral epithelial cells. To this end, we wanted to determine the LPA receptor expression in human oral keratinocytes (HOK), test if the receptors are functionally active, and examine the gene expression profile of HOK exposed to LPA. If indication can be found that LPA can improve oral wound healing, this physiological mediator might be considered for trials aimed at improving healing in acute or chronic oral wounds.

\section{Material and methods}

\section{1. Biopsies and cell cultures}

Biopsies were obtained from healthy volunteers during third molar extractions. The study was approved by Regional Ethical Committee of Health (REK South-East), and was carried out according to the Declaration of Helsinki's principal for biomedical research. Written, informed consent was obtained from all donors. Primary human oral keratinocytes (HOK) were prepared from the biopsies. After transport in Dulbecco's Modified Eagle's Medium (DMEM) (Lonza BioWhittaker, Portsmouth, NH, USA) with $2 \%$ penicillinstreptomycin-fungizone (PSF) (Lonza BioWhittaker), the biopsies were transferred to DMEM with $1.25 \mathrm{mg} / \mathrm{ml}$ dispase (GIBCO, Paisley, UK) and incubated over night at $4{ }^{\circ} \mathrm{C}$. The epithelial sheets were peeled off, cut into small pieces and incubated in $10 \mathrm{X}$ trypsin EDTA (SigmaAldrich, St Louis, MO, USA) for $7 \mathrm{~min}$ at $37^{\circ} \mathrm{C}$. A Pasteur pipette was used to loosen the cells. Trypsinization was stopped by adding fetal calf serum (FCS). The cells were then cultured in keratinocyte serum-free medium (KSFM, GIBCO), supplemented with $25 \mu \mathrm{g} / \mathrm{ml}$ bovine pituitary extract (BPE; GIBCO), $1 \mu \mathrm{g} / \mathrm{ml}$ epidermal growth factor (GIBCO) and $1 \%$ PSF in a humidified atmosphere of $5 \% \mathrm{CO}_{2}$ in air at $37^{\circ} \mathrm{C}$. In the experiments, $2^{\text {nd }}-6^{\text {th }}$ passaged cells were used. For all experiments, the cells were seeded at a desired density, incubated overnight and then grown in KSFM without addition of BPE and EGF $24 \mathrm{~h}$ before stimulation. 


\subsection{Lysophosphatidic acid (LPA)}

LPA 18:1 was purchased from Avanti Polar Lipids (Alabaster, Alabama, USA) and dissolved in fatty acid-free bovine serum albumin (Sigma-Aldrich) in PBS to 2mM and stored at $-20^{\circ} \mathrm{C}$ until use. Fatty acid-free BSA was used as vehicle control in all experiments.

\subsection{RNA isolation, reverse transcription and real-time $q P C R$}

RNA was extracted from cell cultures by the use of RNeasy mini kit (74106; Qiagen, Hilden, Germany). The quantity and purity of the RNA was assessed with a NanoDrop spectrophotometer (ThermoFisher Scientific, Frederick, MD, USA). Total RNA (400 ng) was transcribed into cDNA by using a mixture of reverse transcriptase enzyme and random nonamers (Eurogentec, Seraing, Belgium). Each cDNA synthesis was performed in a total volume of $20 \mu \mathrm{l}$ for $10 \mathrm{~min}$ at $25^{\circ} \mathrm{C}$, then $30 \mathrm{~min}$ at $48^{\circ} \mathrm{C}$ and terminated by incubation for 5 min at $95^{\circ} \mathrm{C}$. Detection of mRNA was performed by using a Fast EvaGreen qPCR Master Mix (Biotium, Hayward, CA, USA). The cDNA was diluted 2.33 times with RNase-free water. Each real time PCR reaction consisted of $2.5 \mu \mathrm{l}$ RNase-free water, $12.5 \mu \mathrm{l}$ Master Mix, $1 \mu \mathrm{l}$ each of forward and reverse primers(LPA1 forward CTTCTACAACGAGTCCATT and reverse AACAGTGATTCCAAGTCC; LPA2 forward GTTTGTAACAGACATTATTC and reverse AATCAGACTCAGGTAGAT ; LPA3 forward CATAGAGGATAGTATTAGC and reverse TTAGAGACAGGTAATCAT; LPA4 forward TGACTTCCAATTCCAAGATTC and reverse AGACAGCACCATTGAGAT:, LPA5 forward AACAACATCCAAGTCCAA and reverse GAAGAGAGAAACGAGAGAG; LPA6 forward TTGGAGTATTCATCTTGACTAC and reverse ACTGACCAGCAACCTT) and $8 \mu$ of template. Reactions were carried out on an Stratagene MX3005p (Agilent Technologies, CA, USA) for 40 cycles ( $95^{\circ} \mathrm{C}$ for $15 \mathrm{~s}, 56^{\circ} \mathrm{C}$ for $1 \mathrm{~min}$ ) after an initial $10 \mathrm{~min}$ incubation at $95^{\circ} \mathrm{C}$. All reactions were performed in duplicate. Glyceraldehyde 3-phosphate dehydrogenase (GAPDH) was used as a reference gene.

\subsection{Illumina ${ }^{\circledR}$ bead array}

Genome-wide transcriptional analysis was performed using Illumina ${ }^{\circledR}$ bead array technique Norwegian Microarray Consortium in Oslo, Norway (project no.: NMC-OSLO-0222). Utilizing the Illumina ${ }^{\circledR}$ TotalPrep $^{\mathrm{TM}}-96$ RNA Amplification Kit, biotin-labeled cRNA was synthesized from $500 \mathrm{ng}$ total RNA by first- and second strand reverse transcription followed by in vitro transcription of cRNA. RNA quantity was determined using a NanoDrop 
Spectrophotometer while RNA size and integrity were determined using the Agilent 2100 Bioanalyzer (Agilent Technologies, Santa Clara, CA, USA) and RNA integrity number (RIN) values. Values above 7 were considered acceptable. All samples had RIN values above 8.750 ng of biotin-labeled cRNA were analyzed using a HumanHT-12 v4 Expression BeadChip. Data from the microarray were filtered and processed using the software program TIBCO Spotfire ${ }^{\circledR}$ (TIBCO Spotfire, Boston, MA, USA). Datasets from the arrays were grouped in Spotfire ${ }^{\circledR}$ and filtered for empty records and genes with signal intensities below the cut-off of 400 set equal to background intensity. Triplicates of datasets from stimulated and unstimulated cells were averaged and fold changes of gene regulation were calculated relative to unstimulated cells.

\subsection{Western Blotting}

HOK were seeded at the desired density (dependent on type of experiments) in 6well plates and incubated overnight. The cells were then cultured for $24 \mathrm{~h}$ in keratinocyte SFM medium (without BPE) before stimulation with LPA $(10 \mu \mathrm{M})$ for another $24 \mathrm{~h}$. The cells were washed twice in cold sterile PBS and then scraped directly in CelLytic M Cell Lysis Reagent (Sigma-Aldrich) with Halt ${ }^{T M}$ Protease Inhibitor Cocktail and EDTA solution (1:100; Pierce, Rockford, IL, USA) on ice. The samples were centrifuged at $4{ }^{\circ} \mathrm{C}$ for $3 \mathrm{~min}$ at $1957 \mathrm{~g}$ and the supernatants were collected. Total protein concentrations were determined using the Bio-Rad protein assay (Bio-Rad, Hercules, CA, USA) with gamma globulin as a standard. In brief, $15 \mu$ g protein were mixed with dithiothreitol (DTT) sample buffer, heated to $100{ }^{\circ} \mathrm{C}$ for 4 min, and loaded on $15 \%$ SDS-polyacrylamide gel. The proteins were transferred to 0.45 $\mu \mathrm{m}$ nitrocellulose membranes using a semi-dry transfer system (Bio-Rad). The membranes were blocked with $4 \%$ bovine serum albumin (Jackson ImmunoResearch Laboratories, West Grove, PA, USA) in Tris buffered saline containing Tween-20 (TBST) for $1 \mathrm{~h}$ at room temperature. The samples were then incubated with primary antibody solution (total p38 [p38 MAPK (D13E1) XP® Rabbit mAb, 1/1000, Cell Signaling Technology, Danvers, MA, USA] or phospho p38 [Phospho-P38 pThr180 / pTyr18, 1:1000, BioSource, Camarillo, CA, USA]), ( total ERK1/2 [p44/42 MAPK (Erk1/2) Antibody; 1:1000, Cell Signaling Technology] or phospho-ERK1/2 [Phospho-p44 MAPK + p42 MAPK pThr185 + pTyr187; 1:1000, BioSource], (total JNK [JNK2 (56G8) Rabbit mAb; 1:1000, Cell Signaling Technology] or phospho-JNK [Phospho-JNK1 + JNK2 pThr183 + pTyr185 Polyclonal Antibody; 1:1000, BioSource]) 
overnight at $4{ }^{\circ} \mathrm{C}$ or for $2 \mathrm{~h}$ at room temperature. The blots were then washed three times in TBST for 10 min followed by incubation with alkaline phosphatase-conjugated donkey antigoat IgG (1:5000; Jackson ImmunoResearch Laboratories) for $1 \mathrm{~h}$ at room temperature. The blots were washed in TBST buffer before visualization with a solution containing BCIP/NBP (5-bromo-4-chloro-3'-indolyphosphate/ nitro-blue tetrazolium). Quantification of IL-36Y protein, phosphorylated ERK1, p-38 and JNK was carried out using the image processing program ImageJ ( Schneider, Rasband \& Eliceiri, 2012).

\subsection{ELISA}

HOK were seeded at a density of approximately 60000 cells $\mathrm{cm}^{-2}$ in 6-well plates and incubated overnight. The cells were then serum-starved for $24 \mathrm{~h}$ before stimulation with LPA $(10 \mu \mathrm{M})$ in keratinocyte SFM medium (without BPE). The conditioned medium was collected after $6 \mathrm{~h}$ or $24 \mathrm{~h}$. IL-6, IL-8 and IL-36y secretion were detected using a Human IL-6 mini TMB ELISA Development Kit (Peprotech, Rocky Hill, NJ, USA), Human IL-8 Mini TMB ELISA Development Kit (Peprotech) and Human IL-36G (IL-1F9) ELISA kit (ThermoFisher Scientific), respectively, according to the manufacturer's protocol. All reactions were performed in duplicate.

\subsection{Statistical analysis}

Statistical analysis was carried out with SigmaPlot 13 software (Systat Software, Inc., San Jose, CA, USA). Comparisons between different time points were performed with one way repeated measures analysis of variance (RM-ANOVA). When there were significant differences $(p<0.05)$, pairwise comparisons were carried out with paired t-tests, using the Holm-Sidak method for adjustment of multiple comparisons. The data were presented as mean \pm standard deviation. For western blotting of IL-36y protein, the paired t-test was used.

\section{Results and discussion}

\subsection{LPA receptor expression and signal transduction in human oral keratinocytes.}

Of the 6 known G protein-coupled receptors (LPA $1-6$ ) (Yanagida, Kurikawa, Shimizu \& Ishii, 2013), $\mathrm{LPA}_{1}, \mathrm{LPA}_{5}$ and $\mathrm{LPA}_{6}$ were predominantly transcribed in unstimulated HOK (Fig. 1). $\mathrm{LPA}_{3}$ was moderately and $\mathrm{LPA}_{2}$ and $\mathrm{LPA}_{4}$ were negligibly expressed. Skin keratinocytes express $\mathrm{LPA}_{1}, \mathrm{LPA}_{2}$ and $\mathrm{LPA}_{3}$ (Sauer et al., 2004), while their expression of LPA, $\mathrm{LPA}_{5}$ and $L P A_{6}$ 
is unknown. Oral carcinoma cell lines express LPA LP-6 $_{\text {at }}$ at different levels (Brusevold et al., 2014). This indicates that the LPA receptor profiles are unique for different cell types.

To determine that the LPA receptors were functionally active in HOK, we investigated the ability of LPA to activate intracellular signaling cascades. LPA induced phosphorylation of ERK1 at 5, 10 and 15 min (Fig. 2; $p<0.05$, RM-ANOVA and paired t-tests). Phosphorylation of ERK2 was induced at $5 \mathrm{~min}$, but did not reach statistical significance. LPA activated phosphorylation of p38 MAPK at 15 min ( $p<0.05$, RM-ANOVA and paired t-tests) (Fig. 2). Phosphorylation of JNK was induced after 5 min ( $p<0.05$, RM-ANOVA and paired t-tests) but rapidly decreased (Fig. 2). The observed MAP kinase activation is in line with studies on other cell types such as OSCC (Hwang, Lee, Park \& Chung, 2012; Brusevold et al., 2014), ovarian cancer cells (Fang et al., 2004) and aortic smooth muscle cells (Hao, Tan, Wu, Xu and Cui, 2010).

\subsection{The gene expression profile of LPA-stimulated human oral keratinocytes}

After establishing that LPA can induce signaling in HOK, we set out to analyze the cells' gene expression after LPA stimulation. LPA significantly regulated a wide range of genes, both at 2 and $6 \mathrm{~h}$. We therefore rather focused on fold changes and chose the group of genes that showed the strongest up-regulation (more than 4-fold at either time point; Table 1) for further study. As outlined below, the majority (27/36) of those genes were found to encode for gene products that participate in the processes of chemotaxis, inflammation, remodeling of extracellular matrix, and cellular growth and motogenicity, all essential for wound healing.

\subsubsection{Chemotaxis and cellular migration}

Chemokines are essential in the early stages of wound healing (Singer \& Clark 1999). Keratinocytes, leukocytes, myofibroblasts and endothelial cells need to be recruited to the wound site to start the healing process (Martin, 1997). Leukocyte recruitment is started minutes and keratinocyte migration 3 - $6 \mathrm{~h}$ after wounding (Martin, 1997).

The transcripts for CXCL1, CXCL2, CXCL8, CCL20 and HB-EGF were strongly upregulated by LPA at $2 \mathrm{~h}$, and all decreased at $6 \mathrm{~h}$ (Table 1). CCL5 increased from 2 to $6 \mathrm{~h}$ (Table 1). ELISA showed that LPA induced secretion of CXCL8 (IL-8) after $6 \mathrm{~h}$ and $24 \mathrm{~h}$ ( $p<$ 0.05; RM-ANOVA, paired t-test) (Fig. 3). This shows that LPA can regulate gene expression and secretion in HOK of chemokines that can attract neutrophils (CXCL1, -2 and -8), im- 
mature dendritic cells (DC), effector/ memory T-cells and B-cells (CCL20) and macrophages (CCL5) (Steude, Kulke \& Christophers, 2002; Weathington et al., 2006; Schutyser, Struyf \& Damme, 2003; Spiekstra et al., 2007). CXCL1, -2 and -8 also increase cellular migration of keratinocytes (Steude et al., 2002; Kroeze et al., 2012). In vivo, LPA promotes macrophage recruitment and accelerates wound closing in rat skin (Balazs et al., 2000). Heparin-binding EGF-like growth factor (HB-EGF) is another major factor promoting migration of skin keratinocytes and fibroblasts (Seeger \& Paller, 2015). Prolonged exposure to high local chemokine concentrations can be detrimental and this matches our finding that the mediators were downregulated after $6 \mathrm{~h}$. This is in line with in vivo data derived from a wound healing model in rats (Demoyer et al., 2000).

In addition to being chemokines, CXCL1, CXCL2 and CCL20 display antimicrobial activity (Yang et al., 2003). Their early and strong expression may therefore be a factor to secure a disrupted epithelial barrier from microbial invasion in the early phases of wound healing, before other antimicrobial systems are established (Pastar et al., 2014). Genes coding for other antimicrobial peptides, such as S100A8 and S100A9, were also upregulated by LPA at $6 \mathrm{~h}$, but their gene expression did not reach four fold.

\subsubsection{Inflammation}

The inflammatory response is an early phase in wound healing and a delicate balance between pro- and anti-inflammatory mediators is crucial in re-achieving tissue homeostasis following injury (Eming, Krieg \& Davidson, 2007).

The expression of several pro-inflammatory genes showed strong upregulation, including IL1F9, IL6, TNF, CSF2 and SGPP2, encoding IL-36y, IL-6, TNF- $\alpha$, GM-CSF and SPP-2, respectively. ELISA showed that LPA induced the secretion of IL- 6 after $6 \mathrm{~h}$ and $24 \mathrm{~h}(\mathrm{p}<0.05$; RM-ANOVA, paired t-tests) (Fig. 3). IL-36y was the third most up-regulated gene at $2 \mathrm{~h}$ (Table 1). We could not detect secretion of IL-36y as measured by ELISA of culture supernatant (data not shown), but Western blotting showed that this gene was translated at $24 \mathrm{~h}$ ( $p<$ 0.05; paired t-test) (Fig. 4). This can be due to restricted or delayed secretion of IL-36Y (> 24 h) as the ELISA assay applied should have sufficient sensitivity to detect low IL-36y levels.

IL-36 $\gamma$ has previously not been shown to be regulated by LPA in any cell type. It increases the expression of CXCL1, CXCL8, CCL3, CCL5, and CCL20 in skin keratinocytes (Foster et al., 2014), and IL-36y might therefore in part be responsible for the observed upregu- 
lation of CXCL1, CXCL8, CCL5 and CCL20. IL- 6 and TNF- $\alpha$ promote wound healing by indirectly stimulating inflammation. IL-6 attracts neutrophils (Gallucci, Sloan, Heck, Murray, \& O'Dell, 2004) and has a proliferative effect on keratinocytes (Barrientos, Stojadinovic, Golinko, Brem \& Tomic-Canic, 2008). IL-6 and TNF- $\alpha$ can have both beneficial and detrimental effects, especially in chronic inflammation (Gabay, 2006; Barrientos et al. 2008). The fact that both cytokines were upregulated at $2 \mathrm{~h}$ and were decreased at $6 \mathrm{~h}$ indicates a response toward tissue homeostasis. GM-CSF increases bone marrow production of myeloid cells and activates tissue resident macrophages and neutrophils (Wicks and Roberts, 2016). SPP-2 plays a role in pro-inflammatory signaling in endothelial cells (Mechtcheriakova et al., 2007). SPP2 has not earlier been reported to be expressed by HOK, nor regulated by LPA.

On the other hand, several inhibitors of inflammation were also upregulated by LPA, including TNFAIP3, TNIP1, IL1RN, IL1R2, IL13RA2, DUSP1, DUSP10 and NFKBIA (Table 1). The gene product of TNFAIP3 inhibits NF-KB activation as well as TNF-mediated apoptosis (Filkor et al., 2013). TNIP1 encodes TNFAIP3 interacting protein 1, which also inhibits NF-KB activation by TNF and several other stimuli (Verstrepen, Carpentier, Verhelst \& Beyaert, 2009). The gene product of IL1RN is a natural inhibitor of the pro-inflammatory effects of IL$1 \alpha$ and IL-1 $\beta$ and modulates a variety of IL-1-related immune and inflammatory responses. IL1R2 acts as a decoy receptor for IL-1 $\alpha$ and IL-1 $\beta$ (Garlanda, Riva, Bonavita \& Mantovani, 2013). IL13RA2 acts as a decoy receptor for IL-13 (Zhang et al., 1997). DUSP1 is a negative regulator for the production of inflammatory cytokines (Huang \& Tan, 2012). DUPS10 modulates gene expression in innate immune cells, and is a negative regulator of inflammatory responses via inactivation of JNK (Patterson, Brummer, O'Brien \& Daly, 2009). NFKBIA is also a gene encoding a negative regulator of NF-KB.

Taken together, the present findings indicate that LPA can contribute to establishment of early inflammation in the oral cavity by increasing transcription of genes encoding potent pro-inflammatory factors in HOK. This was, however, succeeded by a wave of inhibition consisting of downregulation of pro-inflammatory and upregulation of anti-inflammatory factors, which corresponds to well-regulated inflammation needed for successful wound healing. This notion is supported by in vivo studies in rats where LPA reduces mucosal damage and inflammation, and ameliorates intestinal epithelial injury (Sturm et al., 1999).

\subsubsection{Remodeling of extracellular matrix}


The fibrin barrier at the wound site must be dissolved (Steffensen, Häkkinen \& Larjava, 2001). The main enzyme for fibrinolysis is plasmin derived from plasminogen in the blood clot. This activation is facilitated by matrix metalloproteases (MMPs) (Pastar et al., 2014). MMPs also participate in remodeling of extracellular matrix (ECM) components (Visse \& Nagase, 2003). LPA upregulated expression of important genes involved in plasminogen activation, PLAUR and SERPINB2 (Table 1), coding for urokinase-type plasminogen activator receptor (UPAR) and plasminogen activator inhibitor 2 (PAI-2), respectively. The gene expression of PLAU (coding for urokinase-type plasminogen activator, UPA) was also upregulated by LPA, although it did not reach a 4 fold increase. Genes coding for MMP-9 and MMP-10 were also strongly upregulated at 2 and $6 \mathrm{~h}$. ADAMTS1, an ADAM metallopeptidase, was upregulated at $2 \mathrm{~h}$ but decreased at $6 \mathrm{~h}$ (Table 1 ).

UPAR binds the protease UPA which cleaves plasminogen, generating plasmin. Plasmin cleaves and activates MMPs. Both plasmin and MMPs degrade many ECM components and fibrin, and activate growth factors. UPA and plasmin are antagonized by the serpins plasminogen activator inhibitor 1 (PAI-1; SERPINE1) and PAI2 (SERPINB2) (Smith \& Marshall 2010). To avoid excessive proteolysis and tissue damage, a precisely coordinated regulation of this system is required (Li, Chong, Huang \& Tuan, 2003). The finding that LPA regulates PLAU, PLAUR and SERPINB2 matches the upregulation seen in keratinocytes under conditions of re-epithelialization, both in organotypic keratinocyte co-cultures and epidermal lesions in vivo (Bechtel et al., 1998). MMPs are important in the resorption of extracellular matrix components in physiological and pathological processes (Visse \& Nagase 2003). In early wounds, migrating wound keratinocytes express MMP1, MMP9 and MMP10. After re-epithelialization is complete, MMP9 expression is sustained, whereas the expression of the other MMPs is downregulated (Parks, 1999; Steffensen, Häkkinen \& Larjava, 2001). ADAMTS is a protease with diverse roles in cell surface remodeling and regulation of growth factor availability, and in mediating cell-cell-matrix interaction (Roy, Zhang \& Moses, 2006).

Taken together, LPA strongly induces genes in HOK that are involved in degradation and remodeling of the fibrin clot and extracellular matrix, essential for wound healing.

\subsubsection{Cellular growth}

Cell proliferation is fundamental for wound healing. LPA significantly $(p<0.05)$ upregulated expression of genes coding for the growth factors EDN1 and CSF2 (2 and $6 \mathrm{~h}$ ). 
Endothelin-1 protein, the gene product of EDN1, is an autocrine growth factor for human keratinocytes, while suppressing cell differentiation (Tsuboi et al., 1994). GM-CSF (encoded by CSF2) takes part in the inflammatory process as outlined above but is also secreted by keratinocytes shortly after skin wounding (Mann, Breuhahn, Schirmacher, \& Blessing, 2001) and its injection into human skin induces keratinocyte proliferation (Braunstein et al., 1994).

On the other hand, cell proliferation restricting factors such as DKK1 and EFNA1 were upregulated at $2 \mathrm{~h}$ but downregulated at $6 \mathrm{~h}$ (Table 1). DKK1 encodes dickkopf 1 (Dkk1), an inhibitor of Wnt/ $\beta$-catenin pathway (Niehrs, 2006), inhibits epithelial cell proliferation and differentiation (Koch et al., 2011). EFNA1, encoding ephrin-A1, induces cornification while suppressing wound healing-associated genes, and inhibits keratinocyte proliferation (Walsh \& Blumenberg, 2011). This can point to a prioritization of the HOK's response in the early phase of wound healing where they preferentially migrate and not proliferate or differentiate, to close the wound edge (Singer \& Clark, 1999), a process termed restitution. In vivo study in skin keratinocytes supports our finding (Sturm et al., 1999).

\section{Conclusions}

HOK express functional LPA receptors which activate the MAPK intracellular signaling pathways and LPA exposure strongly induced transcription of a range of mediators in the cells. We also detected translation and secretion of selected cytokines. Genes involved in chemotaxis and early inflammation were transiently upregulated and subsequently downregulated in HOK exposed to LPA. Early and intermediate up-regulation of genes involved in remodeling of extracellular matrix and cellular growth was also seen. These observations indicate that LPA, present in saliva and released from activated platelets at an oral wound site, can activate oral keratinocytes to produce essential factors involved in the early phases of wound healing. This means that administration of LPA could be a valuable approach to promote oral wound healing, especially in patients with reduced wound healing capacity, e.g. persons receiving radiotherapy, uncontrolled diabetic patients, and patients receiving high doses of bisphosphonates. 


\section{Acknowledgements}

The authors want to thank Hanne Margrete Weidemann for excellent technical assistance, and Dr. E. B. Hals (Tannlegene i Bogstadveien 51) and Dr. A. Karatsaidis (Galleri Oslo Klinikken), for collection of gingival biopsies.

\section{Author contributions}

All authors contributed to the conception and the design of the study. HHT, SAE and OS acquired data. HHT, SAE, KS and IJB analyzed and interpreted the data. HHT, KS and IJB drafted the article and all authors revised it for important intellectual content, and read and approved the final article. 


\section{References}

Barrientos, S., Stojadinovic, O., Golinko, M. S., Brem, H., \& Tomic-Canic, M. (2008). PERSPECTIVE ARTICLE: Growth factors and cytokines in wound healing. Wound Repair and Regeneration, 16(5), 585-601. doi:10.1111/j.1524-475x.2008.00410.x

Bathena, S., Huang, J., Nunn, M., Miyamoto, T., Parrish, L., Lang, M., ... Alnouti, Y. (2011). Quantitative determination of lysophosphatidic acids (LPAs) in human saliva and gingival crevicular fluid (GCF) by LC-MS/MS. Journal of Pharmaceutical and Biomedical Analysis, 56(2), 402-407. doi:10.1016/j.jpba.2011.05.041

Bechtel, M. J., Wysocki, N. S., Heidtmann, A., Stark, H. J., Fusenig, N., Kramer, M. D., \& Schaefer, B. M. (1998). Plasminogen activator inhibitor type 2 is expressed in keratinocytes during re-epithelialization of epidermal defects. British Journal of Dermatology, 138 (1), 22-28. doi:10.1046/j.1365-2133.1998.02021.x

Blaho, V. A., \& Hla, T. (2011). Regulation of Mammalian Physiology, Development, and Disease by the Sphingosine 1-Phosphate and Lysophosphatidic Acid Receptors. Chemical Review., 111(10), 6299-6320. doi:10.1021/cr200273u

Braunstein S, Kaplan G, Gottlieb AB, Schwartz M, Walsh G, Abalos RM, Fajardo TT, Guido LS, Krueger JG. (1994). GM-CSF activates regenerative epidermal growth and stimulates keratinocyte proliferation in human skin in vivo. Jornal of Investigavtive Dermatology, 103(4), 601-604.

Brusevold, I. J., Tveteraas, I. H., Aasrum, M., Ødegård, J., Sandnes, D. L., \& Christoffersen, T. (2014). Role of LPAR3, PKC and EGFR in LPA-induced cell migration in oral squamous carcinoma cells. BMC Cancer, 14(1), 432. doi:10.1186/1471-2407-14-432

Brandner, J. M., Kief, S., Grund, C., Rendl, M., Houdek, K., Kuhn, C., ... Moll, I. (2002). Organization and formation of the tight junction system in human epidermis and cultured keratinocytes. European Journal of Cell Biology, 81(5), 253-263. doi:10.1078/0171-9335-00244

Cerutis, D. R., Weston, M. D., Alnouti, Y., Bathena, S. P., Nunn, M. E., Ogunleye, A. O., . . Miyamoto, T. (2015). A Major Human Oral Lysophosphatidic Acid Species, LPA 18:1, Regulates Novel Genes in Human Gingival Fibroblasts. Journal of Periodontology, 86(5), 713-725. doi:10.1902/jop.2015.140592

Charbonnier, A., Kohrgruber, N., Kriehuber, E., Stingl, G., Rot, A., \& Maurer, D. (1999). Macrophage Inflammatory Protein $3 \alpha$ Is Involved in the Constitutive Trafficking of Epidermal Langerhans Cells. The Journal of Experimental Medicine, 190(12), 17551768. doi:10.1084/jem.190.12.1755

Chi, H., Barry, S. P., Roth, R. J., Wu, J. J., Jones, E. A., Bennett, A. M., \& Flavell, R. A. (2006). Dynamic regulation of pro- and anti-inflammatory cytokines by MAPK phosphatase 1 (MKP-1) in innate immune responses. Proceedings of the National Academy of Sciences, 103(7), 2274-2279. doi:10.1073/pnas.0510965103

Dickinson, J. L., Bates, E. J., Ferrante, A., \& Antalis, T. M. (1995). Plasminogen Activator Inhibitor Type 2 Inhibits Tumor Necrosis Factor alpha-induced Apoptosis. Evidence for an alternate biological function. Journal of Biological Chemistry, 270(46), 2789427904. doi:10.1074/jbc.270.46.27894 
Dunn, E., Sims, J. E., Nicklin, M. J., \& O'neill, L. A. (2001). Annotating genes with potential roles in the immune system: Six new members of the IL-1 family. Trends in Immunology, 22(10), 533-536. doi:10.1016/s1471-4906(01)02034-8

Eichholtz, T., Jalink, K., Fahrenfort, I., \& Moolenaar, W. H. (1993). The bioactive phospholipid lysophosphatidic acid is released from activated platelets. Biochemical Journal, 291(3), 677-680. doi:10.1042/bj2910677

Eming, S. A., Krieg, T., \& Davidson, J. M. (2007). Inflammation in Wound Repair: Molecular and Cellular Mechanisms. Journal of Investigative Dermatology, 127(3), 514-525. doi:10.1038/sj.jid.5700701

Fang, X., Yu, S., Bast, R. C., Liu, S., Xu, H., Hu, S., . . Mills, G. B. (2003). Mechanisms for Lysophosphatidic Acid-induced Cytokine Production in Ovarian Cancer Cells. Journal of Biological Chemistry, 279(10), 9653-9661. doi:10.1074/jbc.m306662200

Filkor, K., Hegedűs, Z., Szász, A., Tubak, V., Kemény, L., Kondorosi, É, \& Nagy, I. (2013). Genome Wide Transcriptome Analysis of Dendritic Cells Identifies Genes with Altered Expression in Psoriasis. PLOS ONE, 8(9). doi:10.1371/journal.pone.0073435

Foster, A. M., Baliwag, J., Chen, C. S., Guzman, A. M., Stoll, S. W., Gudjonsson, J. E., . . Johnston, A. (2014). IL-36 Promotes Myeloid Cell Infiltration, Activation, and Inflammatory Activity in Skin. The Journal of Immunology, 192(12), 6053-6061. doi:10.4049/jimmunol.1301481

Gabay, C. (2006). Interleukin-6 and chronic inflammation. Arthritis Research \& Therapy, 8(Suppl 2). doi:10.1186/ar1917

Gabay, C., \& Towne, J. E. (2015). Regulation and function of interleukin-36 cytokines in homeostasis and pathological conditions. Journal of Leukocyte Biology, 97(4), 645652. doi:10.1189/jlb.3ri1014-495r

Gallucci, R. M., Sloan, D. K., Heck, J. M., Murray, A. R., \& O'Dell, S. J. (2004). Interleukin 6 Indirectly Induces Keratinocyte Migration. Journal of Investigative Dermatology, 122(3), 764-772. doi:10.1111/j.0022-202x.2004.22323.x

Garlanda, C., Riva, F., Bonavita, E., \& Mantovani, A. (2013). Negative regulatory receptors of the IL-1 family. Seminars in Immunology, 25(6), 408-415. doi:10.1016/j.smim.2013.10.019

Hao, F., Tan, M., Wu, D. D., Xu, X., \& Cui, M. (2010). LPA induces IL-6 secretion from aortic smooth muscle cells via an LPA1-regulated, PKC-dependent, and p38 -mediated pathway. AJP: Heart and Circulatory Physiology, 298(3). doi:10.1152/ajpheart.00895.2009

Huang, C., \& Tan, T. (2012). DUSPs, to MAP kinases and beyond. Cell \& Bioscience, 2(1), 24. doi:10.1186/2045-3701-2-24 
Hwang, Y. S., Lee, S. K., Park, K., \& Chung, W. (2012). Secretion of IL-6 and IL-8 from lysophosphatidic acid-stimulated oral squamous cell carcinoma promotes osteoclastogenesis and bone resorption. Oral Oncology, 48(1), 40-48. doi:10.1016/j.oraloncology.2011.08.022

Kennedy-Crispin, M., Billick, E., Mitsui, H., Gulati, N., Fujita, H., Gilleaudeau, P., . . Krueger, J. G. (2012). Human Keratinocytes' Response to Injury Upregulates CCL20 and Other Genes Linking Innate and Adaptive Immunity. Journal of Investigative Dermatology, 132(1), 105-113. doi:10.1038/jid.2011.262

Koch, S., Nava, P., Addis, C., Kim, W., Denning, T. L., Li, L., ... Nusrat, A. (2011). The Wnt Antagonist Dkk1 Regulates Intestinal Epithelial Homeostasis and Wound Repair. Gastroenterology, 141(1). doi:10.1053/j.gastro.2011.03.043

Kroeze, K. L., Boink, M. A., Sampat-Sardjoepersad, S. C., Waaijman, T., Scheper, R. J., \& Gibbs, S. (2012). Autocrine Regulation of Re-Epithelialization After Wounding by Chemokine Receptors CCR1, CCR10, CXCR1, CXCR2, and CXCR3. Journal of Investigative Dermatology, 132(1), 216-225. doi:10.1038/jid.2011.245

Kumar, S., \& Baglioni, C. (1991). Protection from tumor necrosis factor-mediated cytolysis by overexpression of plasminogen activator inhibitor type-2. Journal of Biological Chemistry, 266(31), 20960-20964.

Kupper, T. S., Min, K., Sehgal, P., Mizutani, H., Birchall, N., Ray, A., \& May, L. (1989). Production of IL- 6 by Keratinocytes. Annals of the New York Academy of Sciences, 557(1), 454-465.

Kurşunlu, S. F., Öztürk, V. Ö, Han, B., Atmaca, H., \& Emingil, G. (2015). Gingival crevicular fluid interleukin-36 $(-1 F 8)$, interleukin-36y (-1F9) and interleukin-33 (-1F11) levels in different periodontal disease. Archives of Oral Biology, 60(1), 77-83. doi:10.1016/j.archoralbio.2014.08.021

Li, W., Chong, S. S., Huang, E. Y., \& Tuan, T. (2003). Plasminogen activator/plasmin system: A major player in wound healing? Wound Repair and Regeneration Wound Repair Regen, 11(4), 239-247. doi:10.1046/j.1524-475x.2003.11402.x

Lobito, A. A., Ramani, S. R., Tom, I., Bazan, J. F., Luis, E., Fairbrother, W. J., . . Gonzalez, L. C. (2011). Murine Insulin Growth Factor-like (IGFL) and Human IGFL1 Proteins Are Induced in Inflammatory Skin Conditions and Bind to a Novel Tumor Necrosis Factor Receptor Family Member, IGFLR1. Journal of Biological Chemistry, 286(21), 1896918981. doi:10.1074/jbc.m111.224626

Mann, A., Breuhahn, K., Schirmacher, P., \& Blessing, M. (2001). Keratinocyte-Derived Granulocyte- Macrophage Colony Stimulating Factor Accelerates Wound Healing: Stimulation of Keratinocyte Proliferation, Granulation Tissue Formation, and 
Vascularization. Journal of Investigative Dermatology, 117(6), 1382-1390. doi: 10.1046/j.0022-202x.2001.01600.x

Martin, P. (1997). Wound Healing--Aiming for Perfect Skin Regeneration. Science, 276(5309), 75-81. doi:10.1126/science.276.5309.75

Marx, R.E. Pamidronate (Aredia) and zoledronate (Zometa) induced avascular necrosis of the jaws: A growing epidemic. J. Oral Maxillofac. Surg. 2003, 61, 1115-1117.

Mechtcheriakova, D., Wlachos, A., Sobanov, J., Kopp, T., Reuschel, R., Bornancin, F., ... \& Zlabinger, G. (2007). Sphingosine 1-phosphate phosphatase 2 is induced during inflammatory responses. Cellular signalling, 19(4), 748-760.

Mills, G. B., \& Moolenaar, W. H. (2003). The emerging role of lysophosphatidic acid in cancer. Nature Reviews Cancer, 3(8), 582-591. doi:10.1038/nrc1143

Miyata, K., Yotsumoto, F., Nam, S. O., Kuroki, M., \& Miyamoto, S. (2012). Regulatory mechanisms of the HB-EGF autocrine loop in inflammation, homeostasis, development and cancer. Anticancer research, 32(6), 2347-2352.

Niehrs, C. (2006). Function and biological roles of the Dickkopf family of Wnt modulators. Oncogene, 25(57), 7469-7481. doi:10.1038/sj.onc.1210054

Palagummi, S., Harbison, S., \& Fleming, R. (2013). A time-course analysis of mRNA expression during injury healing in human dermal injuries. International Journal of Legal Medicine, 128(3), 403-414. doi:10.1007/s00414-013-0941-5

Parks, W. C. (1999). Matrix metalloproteinases in repair. Wound Repair and Regeneration, 7(6), 423-432. doi:10.1046/j.1524-475x.1999.00423.x

Pastar, I., Stojadinovic, O., Yin, N. C., Ramirez, H., Nusbaum, A. G., Sawaya, A., . . TomicCanic, M. (2014). Epithelialization in Wound Healing: A Comprehensive Review. Advances in Wound Care, 3(7), 445-464. doi:10.1089/wound.2013.0473

Patterson, K., Brummer, T., O'brien, P., \& Daly, R. (2009). Dual-specificity phosphatases: Critical regulators with diverse cellular targets. Biochemical Journal, 418(3), 475-489. doi:10.1042/bj20082234

Raber-Durlacher JE, von Bültzingslöwen I, Logan RM, Bowen J, Al-Azri AR, Everaus H, Gerber E, Gomez JG, Pettersson BG, Soga Y, Spijkervet FK, Tissing WJ, Epstein JB, Elad S, Lalla RV; Mucositis Study Group of the Multinational Association of Supportive Care in Cancer/International Society of Oral Oncology (MASCC/ISOO). Systematic review of cytokines and growth factors for the management of oral mucositis in cancer patients. Support Care Cancer. 2013 Jan;21(1):343-55. doi: 10.1007/s00520-012-1594-5. 
Roy, R., Zhang, B., \& Moses, M. (2006). Making the cut: Protease-mediated regulation of angiogenesis. Experimental Cell Research, 312(5), 608-622. doi:10.1016/j.yexcr.2005.11.022

Sauer, B., Vogler, R., Zimmermann, K., Fujii, M., Anzano, M. B., Schäfer-Korting, M., . . . Kleuser, B. (2004). Lysophosphatidic Acid Interacts with Transforming Growth Factor$\beta$ Signaling to Mediate Keratinocyte Growth Arrest and Chemotaxis. Journal of Investigative Dermatology, 123(5), 840-849. doi:10.1111/j.0022-202x.2004.23458.x

Schneider, C. A., Rasband, W. S., \& Eliceiri, K. W. (2012). NIH Image to ImageJ: 25 years of image analysis. Nature methods, 9(7), 671.

Schutyser, E., Struyf, S., \& Damme, J. V. (2003). The CC chemokine CCL20 and its receptor 6101(03)00049-2

Seeger, M. A., \& Paller, A. S. (2015). The Roles of Growth Factors in Keratinocyte Migration. Advances in Wound Care, 4(4), 213-224. doi:10.1089/wound.2014.0540

Singer, A. J., \& Clark, R. A. (1999). Cutaneous wound healing. New England journal of medicine, 341(10), 738-746.

Smith, H. W., \& Marshall, C. J. (2010). Regulation of cell signalling by uPAR. Nature Reviews Molecular Cell Biology, 11(1), 23-36. doi:10.1038/nrm2821

Spiekstra, S. W., Breetveld, M., Rustemeyer, T., Scheper, R. J., \& Gibbs, S. (2007). Woundhealing factors secreted by epidermal keratinocytes and dermal fibroblasts in skin substitutes. Wound Repair and Regeneration, 15(5), 708-717. doi:10.1111/j.1524475x.2007.00280.x

Steffensen, B., Hakkinen, L., \& Larjava, H. (2001). Proteolytic Events of Wound-Healing -Coordinated Interactions Among Matrix Metalloproteinases (MMPs), Integrins, and Extracellular Matrix Molecules. Critical Reviews in Oral Biology \& Medicine, 12(5), 373-398. doi:10.1177/10454411010120050201

Steude, J., Kulke, R., \& Christophers, E. (2002). Interleukin-1-stimulated Secretion of Interleukin-8 and Growth-related Oncogene- $\alpha$ Demonstrates Greatly Enhanced Keratinocyte Growth in Human Raft Cultured Epidermis. Journal of Investigative Dermatology, 119(6), 1254-1260. doi:10.1046/j.1523-1747.2002.19616.x

Sugiura, T., Nakane, S., Kishimoto, S., Waku, K., Yoshioka, Y., \& Tokumura, A. (2002). Lysophosphatidic acid, a growth factor-like lipid, in the saliva. Journal of lipid research, 43(12), 2049-2055. doi: 10.1194/jlr.m200242-jlr200

Tsuboi, R., Sato, C., Shi, C., Nakamura, T., Sakurai, T., \& Ogawa, H. (1994). Endothelin-1 acts as an autocrine growth factor for normal human keratinocytes. J. Cell. Physiol. Journal of Cellular Physiology, 159(2), 213-220. doi:10.1002/jcp.1041590204 
Verstrepen, L., Carpentier, I., Verhelst, K., \& Beyaert, R. (2009). ABINs: A20 binding inhibitors of NF-KB and apoptosis signaling. Biochemical Pharmacology, 78(2), 105-114. doi:10.1016/j.bcp.2009.02.009

Visse, R., \& Nagase, H. (2003). Matrix Metalloproteinases and Tissue Inhibitors of Metalloproteinases: Structure, Function, and Biochemistry. Circulation Research, 92(8), 827-839. doi:10.1161/01.res.0000070112.80711.3d

Walsh, R., \& Blumenberg, M. (2011). Specific and Shared Targets of Ephrin A Signaling in Epidermal Keratinocytes. Journal of Biological Chemistry, 286(11), 9419-9428. doi:10.1074/jbc.m110.197087

Weathington, N. M., van Houwelingen, A. H., Noerager, B. D., Jackson, P. L., Kraneveld, A. D., Galin, F. S., ... \& Blalock, J. E. (2006). A novel peptide CXCR ligand derived from extracellular matrix degradation during airway inflammation. Nature medicine, 12(3), 317-323.

Wicks, I. P., \& Roberts, A. W. (2016). Targeting GM-CSF in inflammatory diseases. Nature Reviews Rheumatology, 12(1), 37-48. doi:10.1038/nrrheum.2015.161

Wong JW, Gallant-Behm C, Wiebe C, Mak K, Hart DA, Larjava H, Häkkinen L. Wound healing in oral mucosa results in reduced scar formation as compared with skin: evidence from the red Duroc pig model and humans. Wound Repair Regen. 2009 Sep-Oct;17(5):717-29. doi: 10.1111/j.1524-475X.2009.00531.x.

Yanagida, K., Kurikawa, Y., Shimizu, T., \& Ishii, S. (2013). Current progress in non-Edg family LPA receptor research. Biochimica Et Biophysica Acta (BBA) - Molecular and Cell Biology of Lipids, 1831(1), 33-41. doi:10.1016/j.bbalip.2012.08.003

Yanagisawa, M., Kurihara, H., Kimura, S., Goto, K., \& Masaki, T. (1988). A novel peptide vasoconstrictor, endothelin, is produced by vascular endothelium and modulates smooth muscle Ca2 channels. Journal of Hypertension, 6(4). doi:10.1097/00004872198812040-00056

Yang, D., Chen, Q., Hoover, D. M., Staley, P., Tucker, K. D., Lubkowski, J., \& Oppenheim, J. J. (2003). Many chemokines including CCL20/MIP-3 $\alpha$ display antimicrobial activity. Journal of leukocyte biology, 74(3), 448-455. doi: 10.1189/jlb.0103024

Zhang, J. G., Hilton, D. J., Willson, T. A., McFarlane, C., Roberts, B. A., Moritz, R. L., ... \& Nicola, N. A. (1997). Identification, Purification, and Characterization of a Soluble Interleukin (IL)-13-binding Protein. Evidence that it is distinct from the cloned IL-13 receptor and IL-4 receptor $\alpha$-chains. Journal of Biological Chemistry, 272(14), 9474-9480. doi: 10.1074/jbc.272.14.9474

Zhao, Y.,\& Natarajan, V., (2009). Lysophosphatidic acid signaling in airway epithelium: role in airway inflammation and remodeling. Cellular signalling, 21(3), 367-77. doi: 10.1016/j.cellsig.2008.10.010 


\section{Figure legends}

Figure 1: Human oral keratinocytes (HOK) express LPA receptor 1, 3, 5 and 6 mRNA. Primary HOK were grown in KSFM with BPE and EGF. Total RNA was extracted and quantitative real time RT-PCR was used to analyze the mRNA expression of LPA $1-6$. The different symbols represent different donors. The values on $y$-axis are normalized against GAPDH reference gene. $n=3$ donors.

Figure 2: LPA activates the MAPK intracellular signaling pathways in human oral keratinocytes (HOK). HOK were grown overnight, and challenged with $10 \mu \mathrm{M}$ LPA for different time periods. Cell lysates were prepared and run in Western blots. Data are presented as mean $\pm S D$. (A) Western blots of phosphorylated and total protein of ERK $1 / 2, p-$ 38 and JNK. (B) Quantification of phosphorylated ERK1, p-38 and JNK. ${ }^{*} p<0.05$ and ${ }^{* *} p<$ 0.001: statistically significant differences compared with control (RM-ANOVA and paired ttests). $n=7$ donors.

Figure 3: LPA induces secretion of IL-6 and IL-8 from human oral keratinocytes (HOK). HOK were grown overnight and challenged with $10 \mu \mathrm{M}$ LPA for $6 \mathrm{~h}$ or $24 \mathrm{~h}$. (A) IL-6 ( $n=5$ donors) and (B) CXCL-8 (IL-8) ( $n=4$ donors) secretion in culture medium was assessed by ELISA. $\mathrm{C}=$ control. Data are presented as mean \pm SD. ND $=$ not detected, ${ }^{*} p<0.05$ : significant differences compared with vehicle control (RM-ANOVA, paired t-test).

Figure 4: LPA induces translation of IL-36y protein in human oral keratinocytes (HOK). HOK were grown overnight, and challenged with $10 \mu \mathrm{M}$ LPA for $24 \mathrm{~h}$. (A) Cell lysates were prepared and run in Western blots. (B) Quantification of IL-36y protein bands on Western blots of stimulated and unstimulated cells. ${ }^{*} p<0.05$ : significant difference compared with vehicle control (C) (paired t-test), $n=5$ donors. 


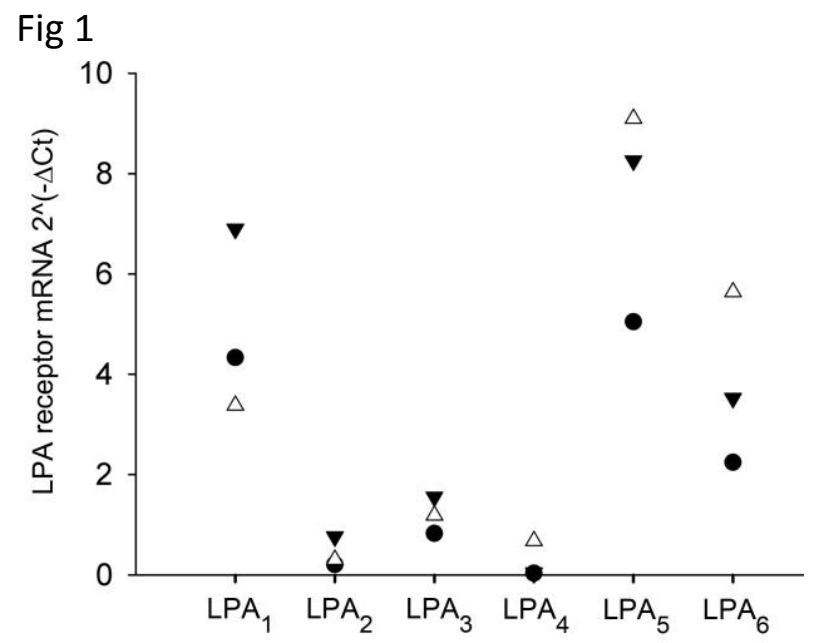

Fig $2 \mathrm{~A}$

A

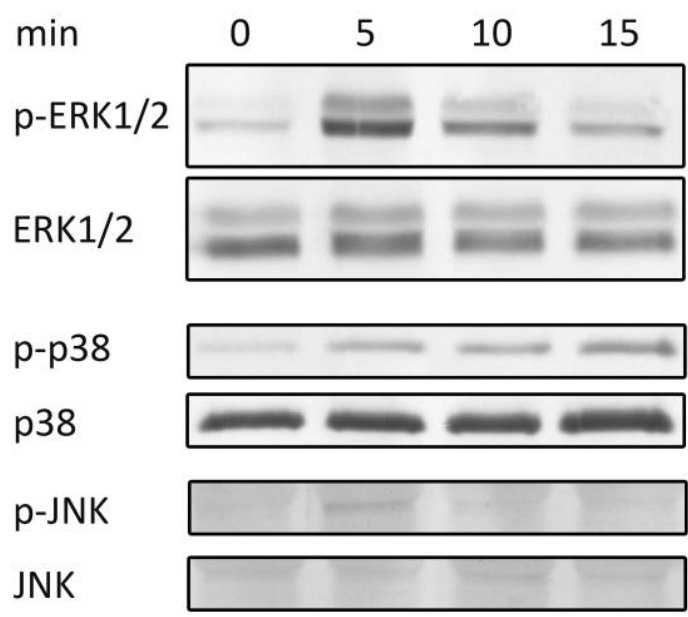


Fig

2B

B
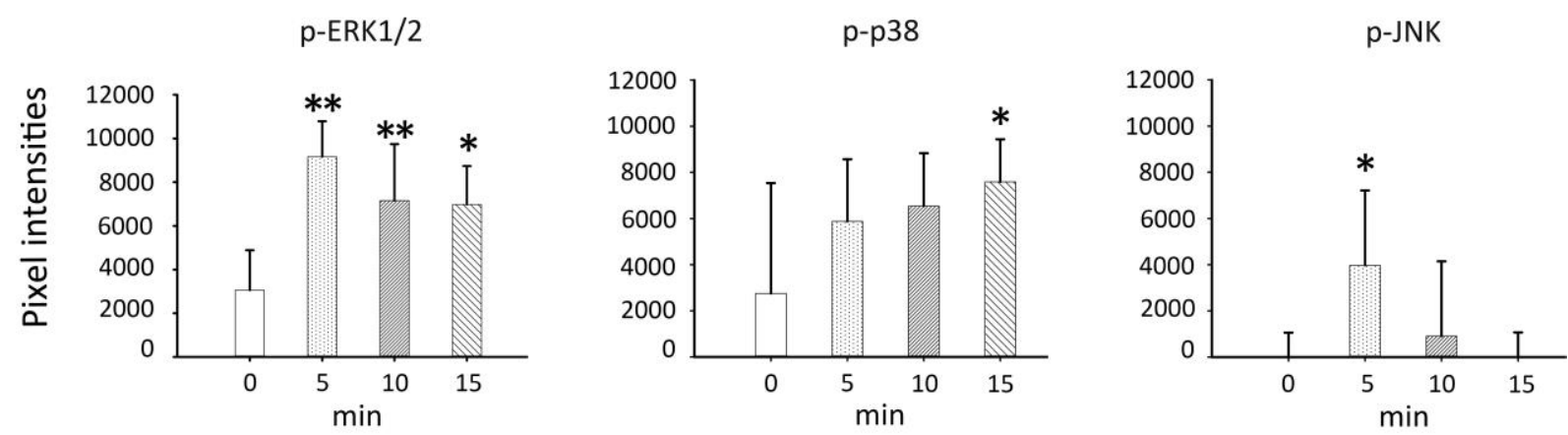

Fig 3
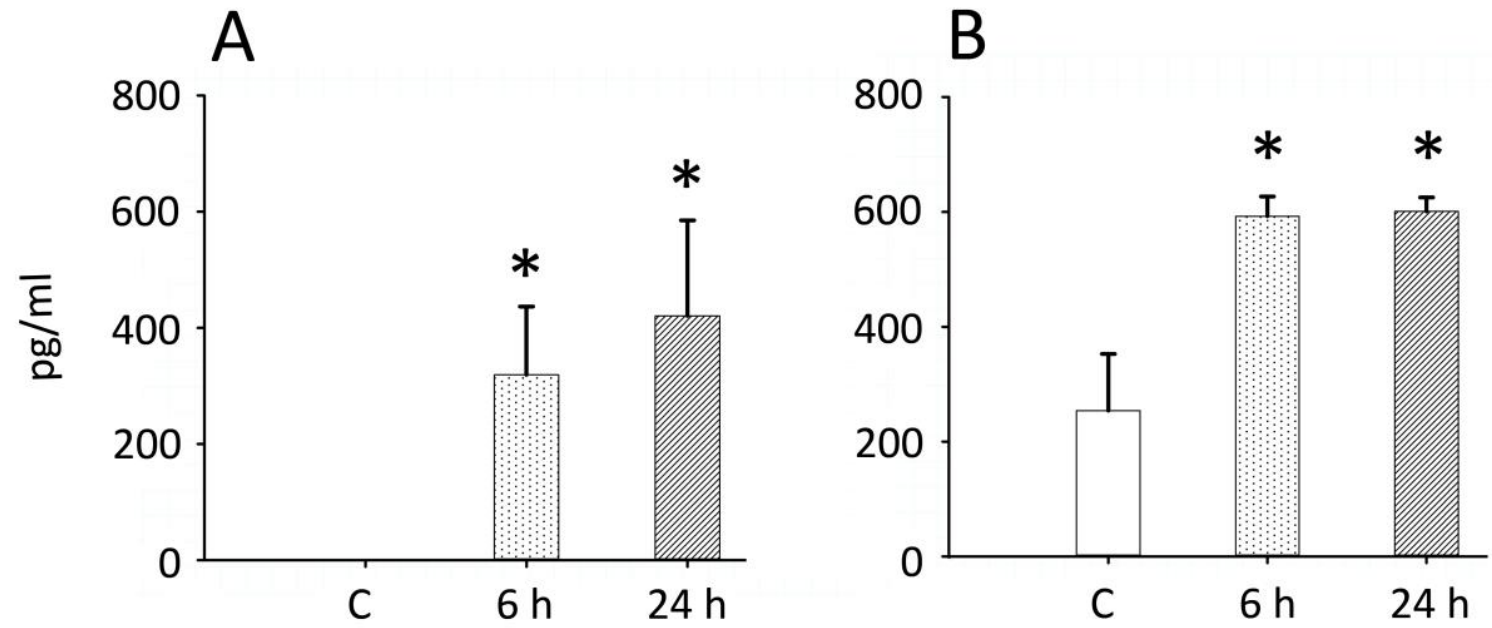

Fig 4

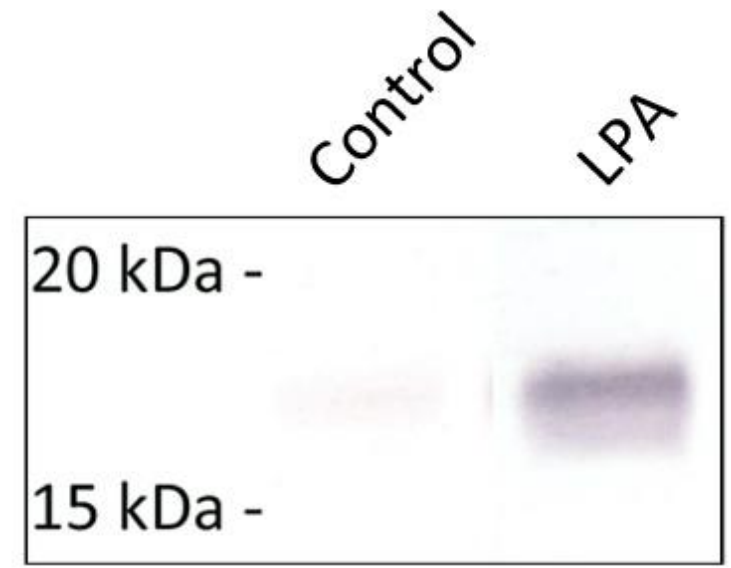

